\title{
FERTILIDADE DO SOLO, ESTADO NUTRICIONAL E PRODUTIVIDADE DE GIRASSOL, EM FUNÇÃO DA APLICAÇÃO DE LODO DE ESGOTO ${ }^{1}$
}

\author{
Victor Sanches Ribeirinho², Wanderley José de Melo $^{3}$, \\ Denis Herisson da Silva ${ }^{4}$, Leila Aparecida Figueiredo ${ }^{5}$, Gabriel Maurício Peruca de Melo ${ }^{6}$
}

\begin{abstract}
SOIL FERTILITY, NUTRITIONAL STATUS, AND YIELD

OF SUNFLOWER FERTILIZED WITH SEWAGE SLUDGE

The disposal of sewage sludge in agricultural soils is of great concern. It can substitute mineral fertilizers, after a proper potassium supplementation, especially in crops such as the sunflower one. This study aimed to evaluate the grain yield and mineral nutrition of the sunflower cv. CATISSOL 01, as well as the fertility of an Oxisol fertilized with sewage sludge, in comparison to mineral fertilization, for two consecutive years. A randomized blocks design, with 4 treatments (control - mineral fertilization, $5 \mathrm{t} \mathrm{ha}^{-1}$ year-1 $^{-1}, 10 \mathrm{t} \mathrm{ha}^{-1}$ year $^{-1}$, and $20 \mathrm{t} \mathrm{ha}^{-1}$ year $^{-1}$ of sewage sludge) and five replicates, was used. Grain yield, macro and micronutrients contents (in diagnostic leaves) and soil fertility were evaluated. The sunflower seeds yield was similar, in all doses, for both the sewage sludge and mineral fertilization, and macro and micronutrients contents in leaves were within the adequate range. The use of sewage sludge enriched with $\mathrm{K}$ showed to be effective for replacing totally or partially mineral fertilization, without affecting the sunflower yield.
\end{abstract}

KEY-WORDS: Helianthus annuus L.; Oxissol; plant nutrition.

\section{INTRODUÇÃO}

O lodo de esgoto é um resíduo originado do tratamento de esgotos domésticos e industriais. Sua disposição final vem se caracterizando como um dos problemas ambientais urbanos mais relevantes da atualidade, pois cresce diariamente, tanto em países desenvolvidos quanto naqueles em desenvolvimento, devido à ampliação das redes de coleta e ao incremento nos níveis de tratamento (Bettiol \& Camargo 2006).

\section{RESUMO}

O lodo de esgoto é um resíduo urbano-industrial que tem causado preocupação, quanto ao uso agrícola. Sua utilização pode ser viável, após a devida suplementação potássica, em substituição a fertilizantes minerais, especialmente em culturas como a do girassol. O presente trabalho objetivou avaliar a produtividade e nutrição mineral do girassol cv. CATISSOL 01, além da fertilidade de um Latossolo Vermelho eutroférrico adubado com lodo de esgoto, em comparação à adubação mineral, por dois anos consecutivos. O experimento utilizou delineamento em blocos casualizados, com 4 tratamentos (fertilização mineral, $5 \mathrm{t} \mathrm{ha}^{-1}$ ano $^{-1}, 10 \mathrm{t} \mathrm{ha}^{-1} \mathrm{ano}^{-1}$ e $20 \mathrm{t} \mathrm{ha}^{-1}$ ano $^{-1}$ de lodo de esgoto) e 5 repetições. Foram analisadas a produtividade de grãos de girassol, a concentração de macro e micronutrientes na folha diagnóstico e a fertilidade do solo. A produtividade de sementes do girassol adubado com o resíduo, em todas as doses, foi equivalente à adubação mineral, e os teores foliares situaram-se na faixa adequada, tanto para macro quanto para micronutrientes. O uso de lodo de esgoto, com suplementação potássica, mostrouse eficiente na substituição total ou parcial da adubação mineral, sem prejudicar a produtividade da cultura do girassol.

PALAVRAS-CHAVE: Helianthus annuus L.; Latossolo Vermelho eutroférrico; nutrição vegetal.

O uso agrícola do lodo de esgoto é considerado uma das alternativas mais viáveis, do ponto de vista econômico e ambiental, para descarte do resíduo, sendo seu uso preconizado, principalmente, em culturas que não são diretamente utilizadas na alimentação humana.

No Brasil, a área cultivada com girassol (Helianthus annuus L.), na safra 2009/2010, ficou em torno de 63,6 mil hectares (Conab 2011). O cultivo pode ser realizado por grandes produtores,

1. Trabalho recebido em out./2011 e aceito para publicação em maio/2012 ( ${ }^{\circ}$ registro: PAT 15858).

2. Instituto Agronômico de Campinas, Centro de Solos e Recursos Ambientais, Campinas, SP, Brasil. E-mail: victor.ribeirinho@gmail.com.

3. Universidade Estadual Paulista, Faculdade de Ciências Agrárias e Veterinárias, Departamento de Tecnologia, Jaboticabal, SP, Brasil.E-mail: wjmelo@fcav.unesp.br.

4. Secretaria de Agricultura e Abastecimento do Estado de São Paulo, Escritório de Desenvolvimento Rural, Piracicaba, SP, Brasil.E-mail: denis.silva@cati.sp.gov.br.

5. Universidade de São Paulo, Centro de Energia Nuclear na Agricultura, Piracicaba, SP, Brasil.E-mail: lafiguei@cena.usp.br. 6. Universidade Camilo Castelo Branco, Centro de Pesquisa em Produção Animal, Descalvado, SP, Brasil.E-mail: gmpmelo@terra.com.br. 
para obtenção de óleo, ou por produtores familiares, que utilizam o girassol em rotações de culturas (Lopes et al. 2009). O óleo, rico em vitamina E, é o principal produto obtido da semente, e o aumento de sua demanda tem sido relacionado à procura por alimentação mais saudável.

O girassol é considerado bastante exigente em nutrientes, sendo que o aumento da produtividade exige quantidades adequadas destes. O lodo de esgoto pode substituir grande parte da adubação mineral, pois é um material rico em carbono, nitrogênio, fósforo e nutrientes, exceto o potássio (Melo et al. 2001). Desta forma, o uso agrícola do lodo de esgoto pode gerar economia e uma destinação sustentável para este resíduo.

A utilização de lodo de esgoto como fertilizante tem aumentado a produtividade de diversas espécies de interesse agronômico (Silva et al. 2010) e, com suplementação potássica, a produtividade pode ser equivalente ou superior à obtida somente com a adubação mineral (Silva et al. 2001). No caso específico do girassol, a substituição do nitrogênio mineral pelo do lodo de esgoto tem sido viável (Lobo \& Grassi Filho 2007).

Por outro lado, o uso incorreto deste resíduo pode contaminar o solo, as plantas e as águas superficiais e subterrâneas com nitratos, fosfatos, metais pesados e outros poluentes presentes (Bettiol \& Ghini 2011). Estudos recentes não constataram aumento significativo de metais pesados em grãos de milho, após aplicações de lodo de esgoto (Trannin et al. 2005, Merlino et al. 2010). Assim, existe o potencial de uso também para outras culturas, como a do girassol.

No Brasil, o Conselho Nacional do Meio Ambiente aprovou, em 2006, a Resolução $n^{\circ} 375$, que define critérios e procedimentos para o uso agrícola de lodos de esgoto sanitário e seus produtos derivados, definindo limites para substâncias potencialmente tóxicas e critérios para liberação do resíduo (Conama 2006). Esta Resolução também define as culturas aptas a receberem lodo de esgoto ou produto derivado, sendo proibida a utilização de lodo de esgoto ou produto derivado em pastagens e cultivo de olerícolas, tubérculos, raízes e culturas inundadas, bem como as demais culturas cuja parte comestível entre em contato direto com o solo (Conama 2006). Portanto, a cultura do girassol está apta a receber fertilização com lodo de esgoto.

O objetivo deste trabalho foi avaliar a utilização do lodo de esgoto como fonte de nutrientes para a cultura do girassol, em comparação com a adubação mineral, observando-se a variação na fertilidade do solo, estado nutricional e produtividade, por dois anos consecutivos.

\section{MATERIAL E MÉTODOS}

O experimento foi realizado no município de Jaboticabal, SP $\left(21^{\circ} 15^{\prime} 22^{\prime}\right.$ 'S, 48 ${ }^{\circ} 15^{\prime} 18^{\prime}$ "W e altitude de $610 \mathrm{~m}$ ), nos anos agrícolas 2004/2005 e 2005/2006. O clima é do tipo Aw, segundo a classificação de Köppen. A planta utilizada foi o Girassol cv. CATISSOL 01. O solo foi classificado como Latossolo Vermelho eutroférrico (Lvf), textura argilosa (Embrapa 2006). Antes da semeadura do girassol, nos dois anos, amostras de solo do tratamento controle foram coletadas para caracterização química, conforme metodologia descrita por Raij et al. (2001) (Tabela 1).

Foi adotado o delineamento experimental em blocos casualizados (DBC), com 4 tratamentos e 5 repetições. Os tratamentos foram classificados como T1 (testemunha - fertilização mineral), T2 (5 t ha $\left.{ }^{-1}\right)$, T3 $\left(10 \mathrm{t} \mathrm{ha}^{-1}\right)$ e T4 $\left(20 \mathrm{t} \mathrm{ha}^{-1}\right)$, à base seca de lodo por ano, empregando-se parcelas subdivididas, com dois anos de avaliação nas subparcelas. A dimensão de cada parcela foi de $8 \mathrm{~m} \times 4 \mathrm{~m}$, com a adoção da técnica de cultivo mínimo. A adubação mineral e as demais práticas foram empregadas conforme recomendação oficial do Estado de São Paulo, para a cultura do girassol (Raij et al. 1997).

Tabela 1. Atributos químicos do solo antes da instalação do experimento e no segundo ano de aplicação do resíduo (Jaboticabal, SP, 2004/2005).

\begin{tabular}{|c|c|c|c|c|c|c|c|c|c|c|}
\hline \multirow{2}{*}{ Ano } & \multirow{2}{*}{$\underset{\mathrm{CaCl}_{2}}{\mathrm{pH}}$} & M.O. & Pres. & $\mathrm{K}^{+}$ & $\mathrm{Ca}^{2+}$ & $\mathrm{Mg}^{2+}$ & $\mathrm{H}^{+}+\mathrm{Al}^{3+}$ & SB & CTC & \multirow{2}{*}{$\frac{\mathrm{V}}{\%}$} \\
\hline & & $\mathrm{g} \mathrm{dm}^{-3}$ & $\mathrm{mg} \mathrm{dm}^{-3}$ & \multicolumn{6}{|c|}{$\mathrm{cmol}_{\mathrm{c}} \mathrm{dm}^{-3}$} & \\
\hline $1^{\circ}$ & 5,5 & 24 & 33 & 0,22 & 4,0 & 3,0 & 2,8 & 7,2 & 10,0 & 72 \\
\hline $2^{\circ}$ & 5,9 & 25 & 61 & 0,28 & 6,2 & 5,0 & 2,2 & 11,4 & 13,6 & 84 \\
\hline
\end{tabular}

M.O.: matéria orgânica; Pres.: P disponível em extrator resina; $\mathrm{K}^{+}$: $\mathrm{K}$ disponível em extrator resina; $\mathrm{Ca}^{2+}$ : Ca disponível em extrator resina; $\mathrm{Mg}^{2+}$ : $\mathrm{Mg}_{\text {disponível em extrator }}$ resina; $\mathrm{H}^{+}+\mathrm{Al}^{3+}$ : acidez potencial; $\mathrm{SB}$ : soma de bases; CTC: capacidade de troca de cátions; V: saturação por bases. Amostragem realizada à profundidade de $0-20 \mathrm{~cm}$. 
O lodo de esgoto utilizado no experimento foi obtido na Estação de Tratamento de Esgoto (ETE) situada em Barueri, região da Grande São Paulo, administrada pela Companhia de Saneamento Básico do Estado de São Paulo (Sabesp), que trata esgoto domiciliar e industrial. Os teores de nutrientes e contaminantes foram determinados após extração com o auxílio do método EPA SW-846-3051 (USEPA 1986) (Tabela 2).

No tratamento T1, a adubação foi realizada utilizando-se, por parcela, no primeiro ano, sulfato de amônio, superfostafo simples, cloreto de potássio e ácido bórico, sendo aplicados $10 \mathrm{~kg} \mathrm{ha}^{-1} \mathrm{de} \mathrm{N}$, $30 \mathrm{~kg} \mathrm{ha}^{-1}$ de $\mathrm{P}_{2} \mathrm{O}_{5}, 30 \mathrm{~kg} \mathrm{ha}^{-1}$ de $\mathrm{K}_{2} \mathrm{O}$ e $1,5 \mathrm{~kg} \mathrm{ha}^{-1}$ de $\mathrm{B}$. No segundo ano, foram utilizados sulfato de amônio, superfostafo simples e cloreto de potássio, aplicando-se $10 \mathrm{~kg} \mathrm{ha}^{-1}$ de N, $20 \mathrm{~kg} \mathrm{ha}^{-1} \mathrm{de}_{2} \mathrm{O}_{5}$ e $30 \mathrm{~kg} \mathrm{ha}^{-1}$ de $\mathrm{K}_{2} \mathrm{O}$. Realizou-se adubação de cobertura aos 45 dias após a semeadura, nos tratamentos testemunhas, aplicando-se uma dose de $40 \mathrm{~kg} \mathrm{ha}^{-1} \mathrm{de}$ $\mathrm{N}$ no primeiro e segundo anos.

No segundo ano, o teor de potássio no lodo foi a metade do observado no primeiro ano, e, por isto, foi realizada uma complementação, na adubação de cobertura, com cloreto de potássio, para que a aplicação de potássio via lodo de esgoto fosse semelhante ao teor do primeiro ano. O tratamento $\mathrm{T} 2$ recebeu $4 \mathrm{~kg} \mathrm{ha}^{-1}$ de $\mathrm{K}_{2} \mathrm{O}$, o tratamento T3 1,45 $\mathrm{kg} \mathrm{ha}^{-1}$ de $\mathrm{K}_{2} \mathrm{O}$ e, no tratamento T4, não foi adicionado $\mathrm{K}_{2} \mathrm{O}$.

O lodo de esgoto, ainda úmido, foi aplicado a lanço e incorporado por meio de gradagem leve $(0,10 \mathrm{~m}$ de profundidade). A área de cultivo foi sulcada, com aplicação do fertilizante mineral em T1. A semeadura foi realizada no espaçamento de $0,8 \mathrm{~m}$ entre as linhas, com oito sementes por metro. Aos 30 dias após a semeadura, realizou-se o desbaste, deixando-se cinco plantas por metro linear.

A amostragem para avaliação do estado nutricional foi realizada no período de florescimento, coletando-se a $5^{\mathrm{a}}$ e $6^{\mathrm{a}}$ folhas abaixo do capítulo, 60 dias após a semeadura (Raij et al. 1997), em 10 plantas por parcela. A seguir, procedeu-se à amostragem do solo, à profundidade de $0-0,20 \mathrm{~m}$, para avaliação da fertili- dade do solo. A amostra composta foi obtida por meio da coleta de 10 amostras simples por parcela, sendo cinco na linha e cinco na entrelinha de plantio. As amostras simples foram reunidas e homogeneizadas, para constituir a amostra composta representativa da parcela. Todas as amostragens de solo e planta foram realizadas a um metro da bordadura, evitando-se o efeito de borda.

As amostras de folhas foram lavadas com solução de detergente diluído, água potável e desionizada e, em seguida, colocadas em estufa com circulação forçada de ar $\left(60-70^{\circ} \mathrm{C}\right)$, até atingir peso constante. As amostras secas foram processadas em moinho tipo Willey, com peneira de 40 mesh.

A digestão do material vegetal foi realizada conforme metodologia proposta por Malavolta et al. (1997), para determinação dos nutrientes, na qual, para o nitrogênio $(\mathrm{N})$, foi feita digestão sulfúrica e, para o fósforo $(\mathrm{P})$, potássio $(\mathrm{K})$, cálcio $(\mathrm{Ca})$, magnésio $(\mathrm{Mg})$, enxofre $(\mathrm{S})$, cobre $(\mathrm{Cu})$, manganês $(\mathrm{Mn})$, ferro $(\mathrm{Fe})$ e zinco $(\mathrm{Zn})$, realizou-se digestão nítrico-perclórica. Os teores de $\mathrm{K}, \mathrm{Ca}, \mathrm{Mg}, \mathrm{Fe}, \mathrm{Mn}$, $\mathrm{Cu}$ e $\mathrm{Zn}$ foram determinados por espectrofotometria de absorção atômica, P por colorimetria do molibdovanadato, $\mathrm{S}$ por turbidimetria do $\mathrm{Ba}_{2} \mathrm{SO}_{4}$ e $\mathrm{N}$ por semi-micro-Kjeldahl.

As amostras de solo foram submetidas à secagem ao ar e na sombra e passadas por peneira $(<2 \mathrm{~mm})$. Em seguida, foi realizada análise química, para avaliação da fertilidade do solo, de acordo com a metodologia do Instituto Agronômico de Campinas, descrita em Raij et al. (2001), determinando-se o seguinte: $\mathrm{pH}$ em $\mathrm{CaCl}_{2}$,, $01 \mathrm{~mol} \mathrm{~L}^{-1}$; P por extração com resina trocadora de íons e determinado pelo

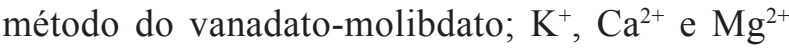
extraídos com resina de troca iônica, sendo o $\mathrm{K}^{+}$ determinado por fotômetro de chama e o $\mathrm{Ca}^{2+} \mathrm{e} \mathrm{Mg}^{2+}$ por espectrofotômetro de absorção atômica; matéria orgânica (M.O.), determinada pelo método colorimétrico do dicromato de sódio; e $\mathrm{H}^{+}+\mathrm{Al}^{3+}$ (acidez potencial), pelo método da solução tampão SMP. A soma de bases (SB), capacidade de troca de cátions (CTC potencial) e saturação por bases (V\%) foram

Tabela 2. Teores de nutrientes e contaminantes no lodo de esgoto utilizado no experimento (Jaboticabal, SP, 2004/2005).

\begin{tabular}{|c|c|c|c|c|c|c|c|c|c|c|c|c|c|c|c|}
\hline \multirow{2}{*}{ Ano } & $\mathrm{N}$ & $\mathrm{P}$ & $\mathrm{K}$ & $\mathrm{S}$ & $\mathrm{Ca}$ & $\mathrm{Mg}$ & $\mathrm{Mn}$ & $\mathrm{Cu}$ & $\mathrm{Fe}$ & $\mathrm{Zn}$ & Mo & $\mathrm{Ni}$ & $\mathrm{Cr}$ & $\mathrm{Cd}$ & $\mathrm{Pb}$ \\
\hline & \multicolumn{6}{|c|}{$-\mathrm{g} \mathrm{kg}^{-1}$} & \multicolumn{9}{|c|}{$-\mathrm{mg} \mathrm{kg}^{-1}$} \\
\hline $1^{\circ}$ & 34,8 & 21,6 & 1,9 & 12,0 & 23,3 & 3,6 & 222 & 726 & 26.070 & 2.589 & 9 & 231 & 808 & 11 & 186 \\
\hline $2^{\circ}$ & 40,9 & 19,5 & 0,9 & 14,6 & 30,6 & 3,8 & 194 & 690 & 25.472 & 2.930 & 10 & 297 & 736 & 11 & 173 \\
\hline
\end{tabular}


calculadas a partir dos valores de $\mathrm{K}^{+}, \mathrm{Ca}^{2+}, \mathrm{Mg}^{2+} \mathrm{e}$ $\mathrm{H}^{+}+\mathrm{Al}^{3+}$.

A determinação da produtividade foi realizada por amostragem de 10 plantas por parcela, coletadas ao acaso e descontando-se a bordadura. A amostragem foi submetida à determinação da massa de grãos de girassol a $11 \%$ de umidade, quando a planta estava na fase R9 (capítulos voltados para baixo).

Os resultados obtidos foram submetidos a análise de variância, pelo teste F. Nos casos em que o teste $\mathrm{F}$ foi significativo, aplicou-se o teste Tukey, a $5 \%$, para separação das médias.

\section{RESULTADOS E DISCUSSÃO}

Não foram observadas diferenças entre os valores de $\mathrm{pH}$, em razão das doses de lodo de esgoto (Tabela 3). O lodo de esgoto utilizado não foi tratado com cal, o que explica a ausência de efeito sobre o $\mathrm{pH}$ do solo, nos dois anos de cultivo. Nascimento et al. (2004), utilizando lodo sem tratamento com cal, observaram redução linear do valor de $\mathrm{pH}$, com o aumento da dose de lodo de esgoto, em diferentes solos. Portanto, a extensão das alterações no pH depende da textura e da capacidade tamponante do solo, do tipo de tratamento do lodo e das doses aplicadas (Oliveira et al. 2002). O tratamento do lodo de esgoto com cal virgem $(\mathrm{CaO})$ ou cal hidratada $\left[\mathrm{Ca}(\mathrm{OH})_{2}\right]$ visa à higienização do mesmo, eliminando diversos agentes patogênicos. Desta forma, existem diversos trabalhos relatando o aumento do valor de $\mathrm{pH}$ do solo, com a aplicação de lodo de esgoto (Melo et al. 2001, Oliveira et al. 2002).

Não foi observada diferença nos teores de matéria orgânica entre as doses de lodo de esgoto (Tabela 3), apesar da elevada concentração de matéria orgânica contida no resíduo. A adição de lodo de esgoto ao solo estimula a atividade microbiana, acelerando a decomposição das frações lábeis e contribuindo para a manutenção dos teores de matéria orgânica (Vaz \& Gonçalves 2002). Assim, o aumento dos teores de matéria orgânica no solo dependerá de aplicações sucessivas do resíduo (Oliveira et al. 2002).

Não foi observada diferença na acidez potencial, soma de bases, CTC potencial e saturação por bases (Tabela 3). Todavia, em estudo similar, Guedes et al. (2006) observaram alta correlação entre o teor de $\mathrm{Ca}^{2+}$ no solo e a soma de bases, em experimento com eucalipto, utilizando doses de lodo de esgoto. A aplicação de lodo de esgoto no solo pode aumentar
Tabela 3. Atributos químicos do solo cultivado com girassol, após adubação mineral e fertilização com lodo de esgoto (Jaboticabal, SP, 2005/2006).

\begin{tabular}{|c|c|c|c|c|c|c|}
\hline \multirow{2}{*}{$\begin{array}{c}\text { Ano } \\
\text { Agrícola }\end{array}$} & \multicolumn{4}{|c|}{ Lodo de esgoto $^{1}$} & \multirow{2}{*}{ Média } & \multirow{2}{*}{$\begin{array}{l}\text { C.V. } \\
(\%)\end{array}$} \\
\hline & $\mathrm{T} 1$ & $\mathrm{~T} 2$ & T3 & T4 & & \\
\hline \multicolumn{7}{|c|}{$\mathrm{pH}$} \\
\hline $1^{\circ}$ & 5,5 & 5,4 & 5,3 & 5,1 & 5,5 & $8,2^{2}$ \\
\hline $2^{o}$ & 5,4 & 5,4 & 5,4 & 5,3 & 5,4 & $1,7^{3}$ \\
\hline Média & 5,5 & 5,4 & 5,4 & 5,2 & & \\
\hline \multicolumn{7}{|c|}{ M.O. $\left(\mathrm{g} \mathrm{dm}^{-3}\right)$} \\
\hline $1^{\circ}$ & 22,0 & 21,0 & 23,0 & 23,0 & 22,0 & $5,8^{2}$ \\
\hline $2^{\circ}$ & 22,0 & 23,0 & 23,0 & 24,0 & 23,0 & $5,5^{3}$ \\
\hline Média & 22,0 & 22,0 & 23,0 & 24,0 & & \\
\hline \multicolumn{7}{|c|}{$\mathrm{H}^{+}+\mathrm{Al}^{3+}\left(\mathrm{cmol}_{c} \mathrm{dm}^{-3}\right)$} \\
\hline $1^{\circ}$ & 2,9 & 3,1 & 3,4 & 3,6 & 3,2 & $20,7^{2}$ \\
\hline $2^{o}$ & 2,9 & 3,4 & 3,2 & 3,7 & 3,3 & $5,2^{3}$ \\
\hline Média & 2,9 & 3,2 & 3,3 & 3,7 & & \\
\hline \multicolumn{7}{|c|}{ Soma de Bases $\left(\mathrm{cmol}_{c} \mathrm{dm}^{-3}\right)$} \\
\hline $1^{\circ}$ & 5,76 & 5,21 & 4,71 & 4,70 & 5,10 & $19,0^{2}$ \\
\hline $2^{o}$ & 5,37 & 5,14 & 5,21 & 5,14 & 5,21 & $8,0^{3}$ \\
\hline Média & 5,57 & 5,18 & 4,96 & 4,92 & & \\
\hline \multicolumn{7}{|c|}{ CTC $\left(\mathrm{cmol}_{\mathrm{c}} \mathrm{dm}^{-3}\right)$} \\
\hline $1^{\circ}$ & 8,64 & 8,31 & 8,07 & 8,30 & 8,33 & $8,4^{2}$ \\
\hline $2^{\mathrm{o}}$ & 8,29 & 8,52 & 8,43 & 8,84 & 8,52 & $4,8^{3}$ \\
\hline Média & 8,47 & 8,42 & 8,25 & 8,57 & & \\
\hline \multicolumn{7}{|c|}{ Saturação por Bases (\%) } \\
\hline $1^{\circ}$ & 66,6 & 62,2 & 58,4 & 56,5 & 60,9 & $14,5^{2}$ \\
\hline $2^{\circ}$ & 65,0 & 60,1 & 61,8 & 57,6 & 61,1 & $4,3^{3}$ \\
\hline Média & 65,8 & 61,1 & 60,1 & 57,1 & & \\
\hline
\end{tabular}

M.O.: matéria orgânica; $\mathrm{H}^{+}+\mathrm{Al}^{3+}$ : acidez potencial; CTC: capacidade de troca de cátions. ${ }^{1} \mathrm{~T} 1=$ fertilização mineral; $\mathrm{T} 2=5 \mathrm{t} \mathrm{ha}^{-1}$ ano $^{-1}$ de lodo de esgoto, base seca; T3 $=10 \mathrm{t} \mathrm{ha}^{-1} \mathrm{ano}^{-1}$ de lodo de esgoto, base seca; $\mathrm{T} 4=20 \mathrm{t} \mathrm{ha}^{-1} \mathrm{ano}^{-1} \mathrm{de}$ lodo de esgoto, base seca. ${ }^{2}$ Coeficiente de variação na parcela. ${ }^{3}$ Coeficiente de variação na subparcela.

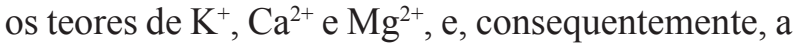
soma de bases (Melo et al. 2001). A CTC, em solos tratados com este resíduo, frequentemente apresenta valores superestimados pela elevada concentração de $\mathrm{Ca}^{2+}$ (Oliveira et al. 2002).

Foi observada interação das doses de lodo de esgoto com os anos de cultivo, para o P do solo (Tabela 4). No primeiro ano, não houve diferença entre as doses de lodo de esgoto aplicadas. No segundo ano, o tratamento $\mathrm{T} 4$ foi o que apresentou maior teor de $\mathrm{P}$, diferindo dos demais. Estes valores podem ser explicados pela aplicação sucessiva de lodo de esgoto e pela mineralização do P orgânico do lodo de esgoto da primeira aplicação. Vários autores relataram que a aplicação de lodo de esgoto foi capaz de aumentar o P disponível no solo (Sui \& Thompson 2000, Bramryd 2001, Simonete et al. 2003).

A adição de material orgânico ao solo promove aumento na disponibilidade de fósforo, pela liberação 
Tabela 4. Teores de nutrientes disponíveis no solo cultivado com girassol, após a adubação mineral e com lodo de esgoto (Jaboticabal, SP, 2005/2006).

\begin{tabular}{|c|c|c|c|c|c|c|}
\hline \multirow{2}{*}{$\begin{array}{c}\text { Ano } \\
\text { Agrícola }\end{array}$} & \multicolumn{4}{|c|}{ Lodo de esgoto $^{1}$} & \multirow{2}{*}{ Média } & \multirow{2}{*}{$\begin{array}{l}\text { C.V. } \\
(\%)\end{array}$} \\
\hline & $\mathrm{T} 1$ & $\mathrm{~T} 2$ & $\mathrm{~T} 30$ & $\mathrm{~T} 4$ & & \\
\hline \multicolumn{7}{|c|}{ Fósforo $\left(\mathrm{mg} \mathrm{dm}^{-3}\right)$} \\
\hline $1^{\mathrm{o}}$ & $42 \mathrm{Aa}$ & $40 \mathrm{Aa}$ & $38 \mathrm{Ab}$ & $49 \mathrm{Ab}$ & 42 & $16,61^{2}$ \\
\hline $2^{o}$ & $46 \mathrm{Ca}$ & $49 \mathrm{Ca}$ & $70 \mathrm{Ba}$ & $118 \mathrm{Aa}$ & 71 & $14,61^{3}$ \\
\hline Média & 44 & 44 & 54 & 84 & & \\
\hline \multicolumn{7}{|c|}{ Potássio $\left(\mathrm{cmol}_{c} \mathrm{dm}^{-3}\right)$} \\
\hline $1^{\mathrm{o}}$ & $0,18 \mathrm{Ab}$ & $0,13 \mathrm{Bb}$ & $0,11 \mathrm{Bb}$ & $0,12 \mathrm{Bb}$ & 0,14 & $10,50^{2}$ \\
\hline $2^{\circ}$ & $0,33 \mathrm{Aa}$ & $0,32 \mathrm{Aa}$ & $0,29 \mathrm{ABa}$ & $0,26 \mathrm{Ba}$ & 0,30 & $10,63^{3}$ \\
\hline Média & 0,26 & 0,23 & 0,20 & 0,19 & & \\
\hline \multicolumn{7}{|c|}{ Cálcio $\left(\mathrm{cmol}_{c} \mathrm{dm}^{-3}\right)$} \\
\hline $1^{\circ}$ & 3,2 & 3,1 & 2,8 & 3,0 & 3,0 & $20,16^{2}$ \\
\hline $2^{\circ}$ & 2,9 & 2,9 & 2,8 & 3,1 & 2,9 & $11,45^{3}$ \\
\hline Média & 3,1 & 3,0 & 2,8 & 3,0 & & \\
\hline \multicolumn{7}{|c|}{ Magnésio $\left(\mathrm{cmol}_{c} \mathrm{dm}^{-3}\right)$} \\
\hline $1^{\mathrm{o}}$ & 2,4 & 2,0 & 1,8 & 1,6 & 1,9 & $17,14^{2}$ \\
\hline $2^{o}$ & 2,1 & 1,9 & 2,1 & 1,8 & 2,0 & $10,01^{3}$ \\
\hline Média & 2,3 & 1,9 & 2,0 & 1,7 & & \\
\hline
\end{tabular}

Valores seguidos de mesma letra maiúscula, na horizontal, e minúscula, na vertical, não diferem entre si, pelo teste Tukey, a 5\%. ${ }^{1} \mathrm{~T} 1$ = fertilização mineral; $\mathrm{T} 2=5 \mathrm{t} \mathrm{ha}^{-1}$ ano $^{-1}$ de lodo de esgoto, base seca; T3 $=10 \mathrm{t} \mathrm{ha}^{-1}$ ano $^{-1}$ de lodo de esgoto, base seca; T4 $=20 \mathrm{t} \mathrm{ha}^{-1}$ ano $^{-1}$ de lodo de esgoto, base seca. ${ }^{2}$ Coeficiente de variação na parcela. ${ }^{3}$ Coeficiente de variação na subparcela.

deste elemento durante o processo de mineralização; dissolução de fosfatos insolúveis em água, devido à ação do ácido carbônico formado pela reação da água com o $\mathrm{CO}_{2}$ proveniente da decomposição do material orgânico; formação de complexos fosfo-húmicos facilmente assimiláveis; formação de fosfatos orgânicos mais fracamente retidos no solo; e revestimento superficial das partículas de argila, evitando o contato direto das mesmas com o fosfato (Oliveira et al. 1995, Marques et al. 1997).

Acrescenta-se que a decomposição do lodo de esgoto produz agentes complexantes que facilitam a movimentação de fosfatos combinados com $\mathrm{Fe}$ e Al, além de permitir melhor aproveitamento dos nutrientes pelas plantas, em decorrência da lenta liberação dos mesmos, pelo processo de mineralização da matéria orgânica (Oliveira et al. 1995, Marques et al. 1997).

Foi observada interação das doses de lodo de esgoto com os anos de cultivo, com relação ao $\mathrm{K}^{+}$do solo (Tabela 4). O aumento do teor de $\mathrm{K}^{+}$no solo, no segundo ano, se deve à complementação de $K$ via adubação mineral, nos tratamentos T2 e T3, e, no tratamento $\mathrm{T} 4$, à baixa lixiviação do $\mathrm{K}^{+}$neste solo e ao acúmulo pela aplicação sucessiva do lodo de esgoto.
Na comparação entre as doses de lodo de esgoto, o tratamento $\mathrm{T} 4$ apresentou menor valor, em comparação ao T1, devido à maior disponibilidade do $\mathrm{K}$ via fertilizante. Entretanto, em todos os tratamentos, as concentrações de $\mathrm{K}$ encontradas na folha diagnóstico ficaram dentro da faixa nutricional adequada para a cultura (Tabela 5). Deve-se, também, levar em conta as características químicas diferentes do lodo de esgoto, entre os anos de cultivo. Os resultados corroboram os relatos de outros autores, que afirmam que a utilização do lodo de esgoto na agricultura deve ser acompanhada de complementação potássica (Ros et al. 1993, Melo et al. 2001).

Não houve diferença nos teores de $\mathrm{Ca}^{2+}$ no solo, entre os tratamentos estudados (Tabela 4). Este fato pode ser explicado pelo uso de lodo de esgoto não tratado com cal, principal fonte de $\mathrm{Ca}$, conforme observado em estudo de Melo et al. (2001). Há au-

Tabela 5. Teores de macronutrientes na folha diagnóstico do girassol e faixas de valores adequados para a cultura do girassol, em $\mathrm{g} \mathrm{kg}^{-1}$ (Jaboticabal, SP, 2005/2006).

\begin{tabular}{|c|c|c|c|c|c|c|}
\hline \multirow{2}{*}{$\begin{array}{c}\text { Ano } \\
\text { Agrícola }\end{array}$} & \multicolumn{4}{|c|}{ Lodo de esgoto $^{1}$} & \multirow{2}{*}{\multicolumn{2}{|c|}{$\begin{array}{ll}\text { Média } & \text { C.V. } \\
& (\%)\end{array}$}} \\
\hline & T1 & $\mathrm{T} 2$ & T3 & $\mathrm{T} 4$ & & \\
\hline \multicolumn{7}{|c|}{ Nitrogênio (teor adequado $2: 30-50$ ) } \\
\hline $1^{\mathrm{o}}$ & 35,92 & 36,58 & 36,99 & 37,15 & 36,66 & $7,81^{3}$ \\
\hline $2^{\circ}$ & 37,76 & 39,89 & 37,49 & 39,90 & 38,76 & $8,10^{4}$ \\
\hline Média & 36,84 & 38,24 & 37,24 & 38,53 & & \\
\hline \multicolumn{7}{|c|}{ Fósforo (teor adequado $\left.{ }^{2}: 3-5\right)$} \\
\hline $1^{\mathrm{o}}$ & 3,39 & 3,92 & 3,99 & 3,92 & 3,80 & $17,32^{3}$ \\
\hline $2^{\mathrm{o}}$ & 3,59 & 4,28 & 4,07 & 4,20 & 4,04 & $10,78^{4}$ \\
\hline Média & 3,49 & 4,10 & 4,03 & 4,06 & & \\
\hline \multicolumn{7}{|c|}{ Potássio (teor adequado²: 30-45) } \\
\hline $1^{\mathrm{o}}$ & 39,90 & 38,83 & 35,38 & 34,32 & 37,10 & $20,77^{3}$ \\
\hline $2^{\mathrm{o}}$ & 42,23 & 42,47 & 36,04 & 36,86 & 39,40 & $10,78^{4}$ \\
\hline Média & 41,06 & 40,65 & 35,71 & 35,59 & & \\
\hline \multicolumn{7}{|c|}{ Cálcio (teor adequado²: 8-22) } \\
\hline $1^{\circ}$ & 21,73 & 22,11 & 23,76 & 25,48 & 23,27 & $13,64^{3}$ \\
\hline $2^{\circ}$ & 22,99 & 24,23 & 24,18 & 27,53 & 24,73 & $10,44^{4}$ \\
\hline Média & $22,36 \mathrm{~B}$ & $23,17 \mathrm{AB}$ & $23,97 \mathrm{AB}$ & $26,51 \mathrm{~A}$ & & \\
\hline \multicolumn{7}{|c|}{ Magnésio (teor adequado²: 3-8) } \\
\hline $1^{\mathrm{o}}$ & 6,00 & 6,66 & 7,88 & 7,25 & 6,95 & $16,68^{3}$ \\
\hline $2^{\circ}$ & 6,38 & 7,33 & 7,99 & 7,79 & 7,37 & $8,02^{4}$ \\
\hline Média & $6,19 \mathrm{~B}$ & $6,99 \mathrm{AB}$ & 7,94 A & 7,52 A & & \\
\hline \multicolumn{7}{|c|}{ Enxofre (teor adequado ${ }^{2}: 1,5-2$ ) } \\
\hline $1^{\circ}$ & 1,65 & 1,80 & 2,17 & 2,11 & 1,93 & $22,01^{3}$ \\
\hline $2^{o}$ & 1,75 & 1,98 & 2,21 & 2,26 & 2,05 & $10,71^{4}$ \\
\hline Média & 1,70 & 1,89 & 2,19 & 2,18 & & \\
\hline
\end{tabular}

Valores seguidos de mesma letra, na horizontal, não diferem entre si, pelo teste Tukey, a $5 \% .{ }^{1} \mathrm{~T} 1=$ fertilização mineral; $\mathrm{T} 2=5 \mathrm{tha}^{-1}$ ano $^{-1}$ de lodo de esgoto, base seca; T3 $=10 \mathrm{t} \mathrm{ha}^{-1} \mathrm{ano}^{-1}$ de lodo de esgoto, base seca; $\mathrm{T} 4=20 \mathrm{tha}^{-1} \mathrm{ano}^{-1}$ de lodo de esgoto, base seca. ${ }^{2}$ Faixas adequadas para a cultura do girassol (Raij et al. 1997). ${ }^{3}$ Coeficiente de variação na parcela. ${ }^{4}$ Coeficiente de variação na subparcela. 
mento nos teores deste nutriente somente em doses acima de 20 t ha $^{-1}$ (Oliveira et al. 1995). Por exemplo, Nascimento et al. (2004) verificaram aumento significativo e linear na disponibilidade de $\mathrm{Ca}$, utilizando doses que variavam de $0 \mathrm{t} \mathrm{ha}^{-1}$ a $60 \mathrm{tha}^{-1}$ de lodo de esgoto tratado com cal, em dois tipos de solos.

Não houve diferença nos teores do $\mathrm{Mg}^{2+}$ no solo, entre os tratamentos avaliados no primeiro e segundo anos (Tabela 4). Aumento gradual na disponibilidade de $\mathrm{Mg}$ tem sido observado pela aplicação de lodo de esgoto ao solo (Marques et al. 1997). Rocha et al. (2004), em experimento com povoamento de eucalipto fertilizado com lodo de esgoto, observaram aumento significativo do teor de $\mathrm{Mg}$ disponível no solo somente após 32 meses da aplicação do lodo.

As concentrações de macronutrientes na folha diagnóstico, em todos os tratamentos, ficaram dentro da faixa nutricional adequada para a cultura do girassol, exceto para o $\mathrm{Ca}$ (Tabela 5). Entretanto, a concentração deste nutriente, mesmo acima do limite, não foi suficiente para afetar a produtividade ou causar qualquer sintoma visual de toxicidade.

$\mathrm{O}$ teor de nitrogênio $(\mathrm{N})$ na folha foi adequado, mostrando que o lodo de esgoto é rico neste nutriente e pode substituir a adubação mineral, corroborando os resultados de Lobo \& Grassi Filho (2007). Os teores de $\mathrm{K}$, mesmo sendo menores que os encontrados no tratamento $\mathrm{T} 1$, situaram-se na faixa adequada para a cultura.

A aplicação de lodo de esgoto promoveu aumento do teor de $\mathrm{Mg}$ na folha (Tabela 5) e diminuição no teor deste elemento no solo (Tabela 4). Acredita-se que sua maior absorção foi devida à aplicação na forma de lodo, que apresenta melhor disponibilidade. Segundo Melo \& Marques (2000), estudos demonstraram que a adição de lodo aumenta a concentração de $\mathrm{Mg}$ nas folhas de cana-de-açúcar, milho e sorgo.

Observou-se, ainda, que a dose mais elevada de lodo de esgoto não causou problemas de excesso de macronutrientes, embora, na maior dose estudada, a aplicação de $\mathrm{N}$ tenha sido de $208 \mathrm{~kg} \mathrm{ha}^{-1}$, quatro vezes acima do valor de $\mathrm{N}$ recomendado para a cultura no Estado de São Paulo (10 kg na semeadura $+40 \mathrm{~kg}$ na cobertura).

As concentrações de micronutrientes também situaram-se dentro das faixas de teores adequados para a cultura (Tabela 6). Comparando-se os tratamentos, houve aumento nos teores de $\mathrm{Cu}$ e $\mathrm{Zn}$ na folha, quando confrontados ao controle e à maior dose estudada $\left(20 \mathrm{t} \mathrm{ha}^{-1}\right)$. Tal fato pode ser explicado pela elevada concentração destes metais no lodo, pois a Estação de Tratamento de Esgoto Barueri trata o esgoto industrial e domiciliar juntos, e os teores de metais no lodo de esgoto são, geralmente, maiores nos resíduos industriais (Bettiol \& Camargo 2006). Pode-se aventar que, a longo prazo, a aplicação contínua deste resíduo possa causar aumentos excessivos destes dois micronutrientes. Experimentos de longa duração são necessários para verificar esta tendência.

No geral, a produtividade de grãos situou-se dentro do intervalo esperado para a cv. CATISSOL 01 $\left(1,5-2,5 \mathrm{t} \mathrm{ha}^{-1}\right)$ e não houve diferença entre o tratamento com adubação mineral (T1) e os demais que receberam doses de lodo de esgoto (Tabela 7).

Tabela 6. Teores de micronutrientes na folha diagnóstico do girassol e faixa de valores adequados para cultura do girassol, em mg kg-1 (Jaboticabal, SP, 2005/2006).

\begin{tabular}{|c|c|c|c|c|c|c|}
\hline \multirow{2}{*}{$\begin{array}{c}\text { Ano } \\
\text { Agrícola }\end{array}$} & \multicolumn{4}{|c|}{ Lodo de esgoto $^{1}$} & \multirow{2}{*}{ - Média } & \multirow{2}{*}{$\begin{array}{l}\text { C.V. } \\
(\%)\end{array}$} \\
\hline & $\mathrm{T} 1$ & $\mathrm{~T} 2$ & T3 & $\mathrm{T} 4$ & & \\
\hline \multicolumn{7}{|c|}{ Cobre (teor adequado $2: 25-100)$} \\
\hline $1^{\mathrm{o}}$ & 42,90 & 56,70 & 56,10 & 57,80 & 53,38 & $20,69^{3}$ \\
\hline $2^{\circ}$ & 41,38 & 62,18 & 57,31 & 61,98 & & 8,70 \\
\hline Média & $42,14 \mathrm{~B}$ & 59,44 & $56,70 \mathrm{AB}$ & $59,89 \mathrm{~A}$ & & \\
\hline \multicolumn{7}{|c|}{ Ferro (teor adequado ${ }^{2}: 80-120$ ) } \\
\hline $1^{\mathrm{o}}$ & 88,73 & 92,84 & 91,60 & 100,03 & 93,30 & $12,99^{3}$ \\
\hline $2^{\circ}$ & 90,28 & 101,60 & 92 & 99,38 & 96,06 & $7,97^{4}$ \\
\hline Média & 89,50 & 97,22 & 92,28 & 99,70 & & \\
\hline \multicolumn{7}{|c|}{ Manganês (teor adequado ${ }^{2}: 10-20$ ) } \\
\hline $1^{\circ}$ & 16,25 & 17,50 & 17,25 & 20,75 & 17,94 & $25,00^{3}$ \\
\hline $2^{\circ}$ & 15,50 & 19,27 & 17 & 22,33 & 18,66 & $9,73^{4}$ \\
\hline Média & 15,87 & 18,39 & 17,40 & 21,54 & & \\
\hline \multicolumn{7}{|c|}{ Zinco (teor adequado $2: 30-80$ ) } \\
\hline $1^{\circ}$ & 46,70 & 72,20 & 73,60 & 82,80 & 68,83 & 22,70 \\
\hline $2^{\circ}$ & 44,77 & 79,16 & 75,15 & 88,25 & 71,83 & 10,23 \\
\hline Média & $45,73 \mathrm{~B}$ & 75,68 & 74,37 A & $85,52 \mathrm{~A}$ & & \\
\hline
\end{tabular}

Valores seguidos de mesma letra, na horizontal, não diferem entre si, pelo teste Tukey, a $5 \%$. ${ }^{1} \mathrm{~T} 1=$ fertilização mineral; $\mathrm{T} 2=5 \mathrm{t} \mathrm{ha}^{-1} \mathrm{ano}^{-1}$ de lodo de esgoto, base seca; T3 $=10 \mathrm{t} \mathrm{ha}^{-1} \mathrm{ano}^{-1}$ de lodo de esgoto, base seca; $\mathrm{T} 4=20 \mathrm{t} \mathrm{ha}^{-1}$ ano $^{-1}$ de lodo de esgoto, base seca. ${ }^{2}$ Faixas adequadas para a cultura do girassol (Raij et al. 1997). ${ }^{3}$ Coeficiente de variação na parcela. ${ }^{4}$ Coeficiente de variação na subparcela.

Tabela7. Produtividade de grãos de girassol fertilizado com adubo mineral e doses de lodo de esgoto (Jaboticabal, SP, 2005/2006).

\begin{tabular}{|c|c|c|}
\hline \multirow{2}{*}{ Tratamento $^{1}$} & $1^{\circ}$ ano & $2^{\circ}$ ano \\
\hline & \multicolumn{2}{|c|}{$\mathrm{t} \mathrm{ha}^{-1}$} \\
\hline T 1 & $1,65 \mathrm{~A}$ & $1,59 \mathrm{~A}$ \\
\hline Т 2 & $1,76 \mathrm{~A}$ & $1,85 \mathrm{~A}$ \\
\hline T 3 & $1,80 \mathrm{~A}$ & $1,70 \mathrm{~A}$ \\
\hline $\mathrm{T} 4$ & $2,03 \mathrm{~A}$ & $2,10 \mathrm{~A}$ \\
\hline C.V. $(\%)$ & 13,72 & 11,40 \\
\hline
\end{tabular}

Valores seguidos de mesma letra não diferem entre si, pelo teste Tukey, a $5 \%$. ${ }^{1} \mathrm{~T} 1=$ fertilização mineral; $\mathrm{T} 2=5 \mathrm{tha}^{-1}$ de lodo de esgoto, base seca; $\mathrm{T} 3=10 \mathrm{tha}^{-1}$ de lodo de esgoto, base seca; $\mathrm{T} 4=20 \mathrm{t} \mathrm{ha}^{-1}$ de lodo de esgoto, base seca. 


\section{CONCLUSÃO}

A utilização de lodo de esgoto é viável para a cultura do girassol, com produtividade equivalente à obtida pela adubação mineral, com teores adequados de macro e micronutrientes na planta, desde que realizada a complementação potássica no lodo. O efeito residual da aplicação sucessiva de lodo de esgoto mostrou ser importante fonte de $\mathrm{P}$ para a cultura, somado ao efeito benéfico da matéria orgânica que, provavelmente, favoreceu a disponibilidade de $\mathrm{P}$.

\section{REFERÊNCIAS}

BETTIOL, W.; CAMARGO, A. O. Lodo de esgoto: impactos ambientais na agricultura. Jaguariúna: Embrapa Meio Ambiente, 2006.

BETTIOL, W.; GHINI, R. Impacts of sewage sludge in tropical soil: a case study in Brazil. Applied and Environmental Soil Science, New York, v. 2011, n. 1, p. 1-11, 2011.

BRAMRYD, T. Effects of liquid and dewatered sewage sludge applied to a Scots pine stand (Pinus sylvestris L.) in central Sweden. Forest Ecology and Management, Amsterdam, v. 147, n. 2, p. 197-216, 2001.

COMPANHIA NACIONAL DE ABASTECIMENTO (Conab). Conjuntura mensal. 2011. Disponível em: $<$ http://www.conab.gov.br/OlalaCMS/uploads/arquivos/ 11f5ab2fd21d8c71cdeba0aa2943fa7d.pdf>. Acesso em: 20 mar. 2011.

CONSELHO NACIONAL DO MEIO AMBIENTE (Conama). Resolução $n^{\circ} .375$ de 29 de agosto de 2006. Define critérios e procedimentos, para o uso agrícola de lodos de esgoto gerados em estações de tratamento de esgoto sanitário e seus produtos derivados, e dá outras providências. Brasília, DF: Conama, 2006.

EMPRESA BRASILEIRA DE PESQUISA AGROPECUÁRIA (Embrapa). Sistema brasileiro de classificação de solos. 2. ed. Rio de Janeiro: EmbrapaCNPS, 2006.

GUEDES, M. C. et al. Propriedades químicas do solo e nutrição do eucalipto em função da aplicação de lodo de esgoto. Revista Brasileira de Ciência do Solo, Viçosa, v. 30, n. 2, p. 267-280, 2006.

LOBO, T. F.; GRASSI FILHO, H. Níveis de lodo de esgoto na produtividade do girassol. Revista de la Ciencia del Suelo y Nutrución Vegetal, Temuco, v. 7, n. 3, p. 16-25, 2007.

LOPES, P. V. L. et al. Produtividade de genótipos de girassol em diferentes épocas de semeadura no oeste da Bahia. Pelotas: Embrapa Clima Temperado, 2009. (Comunicado técnico, 208).

MALAVOLTA, E.; VITTI, G. C.; OLIVEIRA, S. A. Avaliação do estado nutricional das plantas: princípios e perspectivas. 2. ed. Piracicaba: Potafos, 1997.

MARQUES, M. O. et al. Residual effect of sewage sludge on the fertility of a soil cropped with sugarcane. MEETING OF THE INTERNATIONAL SOCIETY OF HUMIC SUBSTANCES, 8., 1997, New York. Proceedings... Wroclaw: ISHS, 1997. p. 419-424.

MELO, W. J.; MARQUES, M. O. Potencial do lodo de esgoto como fonte de nutrientes para as plantas. In: BETTIOL, W.; CAMARGO, O. A. (Eds.). Impacto ambiental do uso agrícola do lodo de esgoto. Jaguariúna: Embrapa Meio Ambiente, 2000. p. 45-67.

MELO, W. J.; MARQUES, M. O.; MELO, V. P. O uso agrícola do biossólido e as propriedades do solo. In: TSUTIYA, M. T. et al. (Eds.). Biossólido na agricultura. São Paulo: Sabesp, 2001. p. 289-363.

MERLINO, L. C. S. et al. Bário, cádmio, cromo e chumbo em plantas de milho e em latossolo após onze aplicações anuais de lodo de esgoto. Revista Brasileira de Ciência do Solo, Viçosa, v. 34, n. 6, p. 2031-2039, 2010.

NASCIMENTO, D. A. et al. Alterações químicas em solos e crescimento de milho e feijoeiro após aplicação de lodo de esgoto. Revista Brasileira de Ciência do Solo, Viçosa, v. 28, n. 2, p. 385-392, 2004.

OLIVEIRA, F. C. et al. Lodo de esgoto como fonte de macronutrientes para a cultura do sorgo granífero. Scientia Agricola, Piracicaba, v. 52, n. 2, p. 360-367, 1995.

OLIVEIRA, F. C. et al. Efeitos de aplicações sucessivas de lodo de esgoto em Latossolo Amarelo distrófico cultivado com cana-de-açúcar: carbono orgânico, condutividade elétrica, pH e CTC. Revista Brasileira de Ciência do Solo, Viçosa, v. 26, n. 2, p. 505-519, 2002.

RAIJ, B. V. et al. Análise química para avaliação da fertilidade de solos tropicais. Campinas: Instituto Agronômico, 2001.

RAIJ, B. V. et al. Recomendações de adubação e calagem para o Estado de São Paulo. 2. ed. Campinas: Instituto Agronômico, 1997. (Boletim técnico, 100).

ROCHA, G. N.; GONCALVES, J. L. M.; MOURA, I. M. Mudanças da fertilidade do solo e crescimento de um povoamento de Eucalyptus grandis fertilizado com biossólido. Revista Brasileira de Ciência do Solo, Viçosa, v. 28, n. 4, p. 623-639, 2004.

ROS, C. O. da et al. Biossólido: efeito imediato no milheto e residual na associação aveia-preta-ervilhaca. Revista Brasileira de Ciência do Solo, Viçosa, v. 17, n. 2, p. 257 261, 1993. 
SILVA, F. C. et al. Efeito do lodo de esgoto na fertilidade de um Argissolo Vermelho-Amarelo cultivado com canade-açúcar. Pesquisa Agropecuária Brasileira, Brasília, DF, v. 36, n. 5, p. 831-840, 2001.

SILVA, H. P. et al. Qualidade física de sementes de girassol produzido sob doses de lodo de esgoto. Revista Verde, Mossoró, v. 5, n. 1, p. 1-6, 2010.

SIMONETE, M. A. et al. Efeito do lodo de esgoto em um argissolo e no crescimento e nutrição de milho. Pesquisa Agropecuária Brasileira, Brasília, DF, v. 38, n. 10, p. 11871195, 2003.

SUI, Y.; THOMPSON, M. L. Phosphorus sorption, desorption and buffering capacity in a biosolids amended mollisol. Soil Science Society of America Journal, Madison, v. 64, n. 1, p. 164-169, 2000.
TRANNIN, I. C. de B.; SIQUEIRA, J. O.; MOREIRA, F. M. de S. Avaliação agronômica de um biossólido industrial para a cultura do milho. Pesquisa Agropecuária Brasileira, Brasília, DF, v. 40, n. 3, p. 261-269, 2005.

UNITED STATES ENVIRONMENTAL PROTECTION AGENCY (USEPA). Test method for evaluating solid waste: report number SW-846. Washington, DC: USEPA, 1986.

VAZ, L. M.; GONÇALVES, J. L. M. Uso de biossólidos em povoamento de eucalipto: efeito em atributos químicos do solo, no crescimento e na absorção de nutrientes. Revista Brasileira de Ciência do Solo, Viçosa, v. 26, n. 3, p. 747-758, 2002. 